\title{
El impacto de la revolución rusa en las organizaciones obreras españolas (1917-1923)
}

\author{
JUAN AVILÉS FARRÉ
}

\begin{abstract}
RESUMEN
La revolución comunista rusa despertó inicialmente un gran entusiasmo en las organizaciones obreras españolas, de tal manera que en 1919 tanto el PSOE como la CNT se pronunciaron por la incorporación a

la recién creada Internacional Comunista. Muy pronto, sin embargo, se puso de manifiesto la incompatibilidad entre la cultura política bolchevique y la de los dos grandes corrientes del obrerismo revolucionario español, que no tardaron en rechazar el modelo de dictadura establecido en Rusia. Sólo un sector muy minoritario de la militancia obrera se incorporó al nuevo Partido Comunista de España.
\end{abstract}

PALABRAS CLAVE Revolución rusa, España, comunismo, socialismo, anarquismo.

\section{ABSTRACT}

The Russian Communist Revolution initially arosed great entusiasm among the Spanish working class

organizations, so that in 1919 both the PSOE end the CNT opted for joining the newly founded Communist International. But very soon the incompatibility between the Bolshevik political culture and those of the two great currents of the Spanish revolutionary working class manifested itself, and both rejected the dictatorship established in Russia. Only a minoritary fringe of the militant workers joined the new PCE.

KEYWORDS

Russian Revolution, Spain, Communism. Socialism, Anarchism. 
La revolución rusa de 1917 dio origen al primer intento de crear un nuevo tipo de sociedad basado enteramente en principios colectivistas, poniendo así en práctica una aspiración que desde al menos medio siglo antes era compartida por numerosos militantes revolucionarios de distintos países. Lo que era una utopía, debatible sólo en el terreno de las ideas, se convirtió así en una experiencia real, susceptible por tanto de análisis empírico. Pero de ese análisis se podían obtener conclusiones muy distintas. Unos entendieron que en Rusia se había hallado el camino que llevaba al mundo feliz del colectivismo, conclusión que llevó al desarrollo de un movimiento comunista internacional basado en las doctrinas de Lenin. Otros, por el contrario, creyeron que la experiencia rusa demostraba la inviabilidad de todo proyecto colectivista y las nefastas consecuencias de intentar llevario a la práctica, argumento que sería repetido una y otra vez por los anticomunistas de todo el mundo. Y por último algunos llegaron a una tercera conclusión, la de que el colectivismo seguía siendo una opción válida, pero que sólo podría establecerse por métodos sustancialmente distintos a los adoptados por los comunistas rusos. El propósito de este ensayo es mostrar como ésta última fue la conclusión a la que, tras una etapa inicial de deslumbramiento ante el triunfo bolchevique, llegaron muy pronto las dos grandes corrientes, socialista y anarcosindicalista, del movimiento obrero español ${ }^{1}$.

\section{LAS PRIMERAS REACCIONES}

La toma del poder por los bolcheviques rusos, que se consideraban los más fieles discípulos de Marx, fue inicialmente acogida con marcada frialdad por los marxistas del PSOE y despertó en cambio el entusiasmo de los anarcosindicalistas, a pesar que éstos se situaban en la tradición de Bakunin. La doble razón de esta aparente paradoja fue que los socialistas españoles estaban preocupados sobre todo por el resultado de la primera guerra mundial y vieron desde esa perspectiva los acontecimientos rusos, mientras que los anarcosindicalistas prestaron más atención a la radicalidad revolucionaria de los bolcheviques que a su filiación marxista?

Para un análisis del impacto de la revolución rusa en España véase J. AVILÉs FARRE (1999): La fe que vino de Rusia: la revolución bolchevique y los españoles, 1917-1931, Madrid. Biblioteca Nueva.

El estudio más completo sobre el movimiento obrero español en este periodo es el el de G. MEAKER (1978): La izquierda revolucionaria en España, 1914-1923, Barcelona, Ariel. Sobre el impacto de la I Guerra Mundial véase C. FORCADELL (1978): Parlamentarismo y bolchevización: el movimiento obrero español. 1914-1918, Barcelona, Critica. 
La mayor parte de los dirigentes del PSOE estaban por entonces convencidos de que la victoria de los aliados resultaría ventajosa para el socialismo europeo, ya que significaría el triunfo de la democracia, aunque fuera burguesa, frente al autoritarismo conservador del Imperio Alemán. Sólo unos pocos, como Manuel Núñez de Arenas o Mariano García Cortés, defendían la tesis, más acorde con la tradición marxista, de que en una guerra entre potencias burguesas ambos bandos representaban intereses contrarios a los del proletariado. El Socialista interpretó en clave aliadófila la revolución rusa de febrero de 1917 y entendió que, tras la caída del zarismo, una nueva Rusia democrática sería un miembro más fiable de la gran coalición de pueblos que se enfrentaba al imperialismo alemán. En el verano de 1917 el PSOE participó, junto a dirigentes republicanos como Melquiades Álvarez y Alejandro Lerroux, en un intento de realizar una revolución semejante a la rusa de febrero, es decir de orientación democrática, aunque dicho intento se frustró tras el fracaso de la huelga general de agosto.

Los anarquistas y sindicalistas que dirigían la CNT o militaban en distintos grupos ácratas fueron mucho menos sensibles a los argumentos aliadófilos, aunque estos fueran defendidos por una figura tan prestigiosa del anarquismo internacional como era Piotr Kropotkin, y tampoco se sintieron especialmente conmovidos porque en Rusia la autocracia zarista fuera a ser sustituida por una democracia burguesa. Pero en muy pocas semanas cambiaron las tornas: los socialistas empezaron a comprender que el pueblo ruso era contrario a la continuación de la guerra y que por tanto la revolución ponía en peligro el triunfo aliado, mientras que los anarcosindicalistas comenzaron a ver en la proliferación de los consejos de obreros y de soldados, los soviets, el inicio de una revolución que no iba a ser meramente burguesa.

Frente a la revolución de octubre, es decir la toma del poder por los bolcheviques, que eran firmes partidarios de firmar la paz por separado y así lo hicieron pocos meses después, los socialistas españoles mantuvieron un largo silencio. No iban a criticar abiertamente a quienes estaban llevando a cabo una revolución socialista, pero les preocupaba que ésta se hubiera traducido en mejores perspectivas bélicas para el Imperio Alemán. En cambio muchos anarquistas, por ejemplo los que editaban en Barcelona la revista Tierra y Libertad, colmaron de elogios a los bolcheviques. Solidaridad Obrera, el diario que era portavoz de la CNT y dirigía Ángel Pestaña, publicó alguna opinión más prudente, junto con otras también muy favorables al bolchevismo. En la propia Rusia los anarquistas habian colaborado inicialmente con los bolcheviques y del posterior enfrentamiento entre unos y otros, que se inició en abril de 1918 y pronto llevó a la derrota total de los primeros, apenas se tuvo noticias en España. 
Las circunstancias cambiaron una vez más cuando el armisticio de noviembre de 1918 puso fin a la I Guerra Mundial y con ella a la aliadofilia de los socialistas españoles. Vencidos los imperios centrales, ya no había motivo para silenciar discretamente el carácter burgués de las democracias occidentales, mientras que se abrían nuevas perspectivas revolucionarias en Alemania, en Austria y en Hungría. Un mitin celebrado en la Casa del Pueblo de Madrid en enero de 1919 fue la primera gran manifestación pública de la naciente admiración del PSOE por la Rusia soviética.

\section{ANTE LA III INTERNACIONAL}

Ambas corrientes del obrerismo español eran internacionalistas. Nadie concebia que la marcha hacia una nueva sociedad pudiera realizarse por separado en cada una de las naciones, pero a la altura de 1918 tanto los socialistas como los anarcosindicalistas españoles carecían de un cauce efectivo de coordinación internacional. EI PSOE formaba parte de la II !nternacional, fundada en 1889, pero ésta había sufrido un golpe demoledor con el estallido de la guerra mundial, en el curso de la cual sus secciones nacionales habian apoyado en su mayoría el esfuerzo bélico de sus respectivos gobiernos. Por su parte la CNT no tenía vínculo orgánico alguno con organizaciones de otros países. En tales circunstancias y dado el creciente entusiasmo de los militantes obreros españoles por la revolución rusa, el llamamiento lanzado por la Internacional Comunista (o III Internacional), que se fundó en Moscú en marzo de 1919, tuvo un gran eco tanto en el PSOE como en la CNT. Durante casi cuatro años el dilema de incorporarse o no a la nueva Internacional resultó crucial en la dinámica interna de ambas organizaciones.

El debate resultó complejo y prolongado, debido a las exigencias que implicaba la adhesión a la III Internacional. Los bolcheviques no estaban dispuestos a aceptar el ingreso de ningún partido que no se hubiera librado de sus elementos más moderados, como habian hecho ellos al romper con los mencheviques, lo que chocaba con la fuerte identificación con la unidad del partido que caracterizaba a los militantes del PSOE. El propio radiograma con el que se había convocado el congreso fundacional de la Internacional Comunista, en el que realmente no pudo participar casi ningún delegado extranjero, había invitado al mismo tan sólo a «los elementos de izquierda del Partido Socialista Español», lo que parecía excluir a su sector mayoritario, cuya ostensible aliadofilia era desde la perspectiva de Moscú una prueba inequívoca de derechismo. Sin embargo dicho sector tampoco era partidario de una reconsirucción de la ll Internacional que 
implicara una marginación de los bolcheviques. Ello se comprobó en la conferencia socialista internacional celebrada en Berna en febrero de 1919, en la que el delegado del PSOE, Julián Besteiro, se opuso a la resolución mayoritaria, presentada por el sueco Branting, que identificaba plenamente al socialismo con la democracia y por lo tanto condenaba implicitamente los métodos bolcheviques.

Pocos meses después la Agrupación Socialista madrileña pidió un referendum en el que los militantes socialistas pudieran pronunciarse por la integración en la Internacional Comunista. Frente a ello la dirección del PSOE, encabezada por Pablo Iglesias, inició una táctica dilatoria, que mantendría durante dos años, con el objetivo de evitar una escisión, tanto del propio PSOE, entre cuyos militantes de base la corriente favorable a la Internacional Comunista era por entonces posiblemente mayoritaria, como del conjunto del socialismo internacional, que corría el riesgo de escindirse en dos organizaciones rivales. Para Iglesias y para sus colaboradores más estrechos, entre los que destacaba Besteiro, la unidad socialista tenía un gran valor y para mantenerla celebraron tres congresos extraordinarios sucesivos, en los que trataron de hallar fórmulas de consenso respecto a la difícil cuestión de la Internacional. Por entonces El Socialista publicó casi exclusivamente opiniones favorables a la revolución bolchevique, ignorando las críticas de los mencheviques rusos y de destacadas figuras del socialismo europeo como Karl Kautsky ${ }^{3}$.

En el primero de aquellos congresos extraordinarios, celebrado en Madrid en diciembre de 1919, se impuso por estrecho margen una compleja resolución, según la cual el PSOE permanecería de momento en la II Internacional, pero propondría en el inminente congreso que ésta iba a celebrar la fusión de ambas internacionales y, si dicha propuesta era rechazada, abandonaría la II para incorporarse a la III. Ello representaba un aplazamiento de la decisión que no fue del agrado de las Juventudes Socialistas, las cuales acordaron en su propio congreso, celebrado inmediatamente después, la adhesión incondicional a la II!.

La CNT celebró también un congreso en Madrid en ese mismo mes de diciembre de 1919 y no eludió en él la cuestión de la Internacional. Por entonces la confederación estaba en pleno auge y en ella predominaban las expectativas de una próxima revolución. Desde 1918 había experimentado un espectacular crecimiento, sobre todo en Barcelona y su comarca, donde

No tuvo apenas eco en las tilas del PSOE la importante obra en que este pensador marxista criticó la política bolchevique, de la que se publicó por entonces una versión española: K. KAUTSKY (1920?): Terrorismo y comunismo, Madrid, Biblioteca Nueva. 
se desarrollaron duras batallas huelguísticas, en el curso de las cuales sus militantes recurrieron a menudo a una acción terrorista, basada en atentados personales, a la que pronto se contrapondría un contraterrorismo impulsado por las autoridades, por la patronal y por una organización obrera rival de orientación derechista, los Sindicatos Libres ${ }^{4}$. Y en el campo andaluz los militantes anarquistas impulsaron en aquellos años una agitación reivindicativa, que se vio estimulada por las noticias del reparto de la tierra que había tenido lugar en Rusia, por lo que ha pasado a la historia con la denominación de trienio bolchevista ${ }^{5}$. Así es que el ambiente en el congreso de la CNT no podía ser más que de exaltación revolucionaria y de admiración sin límites por el ejemplo ruso, lo que condujo a que se adoptara una resolución firmemente revolucionaria pero un tanto contradictoria, pues al tiempo que proclamaba la fidelidad de la CNT a los principios de Bakunin acordaba la adhesión a la III Internacional, aunque sólo fuera provisionalmente, en tanto no llegara a fundarse la verdadera Internacional de los Trabajadores.

El equivoco presidió pues el congreso de la CNT no menos que el del PSOE. En diciembre de 1919 los anarcosindicalistas españoles acordaron ir al encuentro de Lenin en nombre de Bakunin, mientras que los socialistas resolvieron proponer el acuerdo con Moscú a la II Internacional, a pesar de que ésta acababa de proclamar en la conferencia de Berna su identificación con las libertades democráticas.

\section{EL NACIMIENTO DEL PCE}

Hasta entonces los dirigentes soviéticos no habían mostrado interés alguno por España; un país del que muy poco sabian, aunque Trotski lo había visitado en 1916 (bien contra su voluntad, pues lo hizo por haber sido deportado de Francia y pasó en la cárcel una parte de su breve estancia en nuestro país). Fue en aquel mismo mes de diciembre de 1919 cuando, un poco por casualidad, llegaron a España procedentes de México dos agentes de la lil Internacional, el ruso Mijail Borodin, que más tarde jugaría un papel importante en China, y un norteamericano de apellido Phillips que se hacia pasar con éxito por mexicano y se hacía llamar Jesús Ramírez ${ }^{6}$.

4 Véase A. BALCELLS (1987): "Violencia y terrorismo en la lucha de clases en Barcelona de 1913 a 1923", en Estudios de Historia Social, n. ${ }^{\circ} 1,42-43$.

5 La obra ciásica sobre el tema es la de J. DIAZ DEL MORAL (1929): Historia de las agitaciones campesinas andaluzas: Córdoba.

6 Véase J. Avilés FarRÉ (2000): "Le origini del Partito Comunista di Spagna, 1920-1923", en Ricerche di Storia Politica, año $3, n .{ }^{\circ} 1,1$. 
A través de ellos, los socialistas españoles que eran partidarios de la III Internacional pudieron por primera vez entrar en contacto directo con ella. Borodin y Ramírez se reunieron con los principales dirigentes del ala de izquierda del PSOE, pero la reticencia de éstos a provocar una escisión de su partido pronto los decepcionó. Ramírez dudaba incluso de la sinceridad revolucionaria de alguno de ellos y especialmente de Mariano García Cortés, no sin motivo en el caso de éste último, cuya breve etapa comunista concluiría con su incorporación al grupo liberal del conde de Romanones. Así es que el supuesto mexicano terminó por favorecer la singular decisión de que fueran las Juventudes Socialistas las que se transformaran en Partido Comunista Español. Esto ocurrió el 15 de abril de 1920, fecha en la que Ramón Merino, hasta entonces secretario general de las JJSS pasó a serlo del PCE, aunque sus convicciones comunistas tampoco resultaron muy firmes, pues al parecer no tardó en abandonarlas para incorporarse nada menos que a los Sindicatos Libres ?

Su juventud valió a los miembros del naciente PCE el apelativo de “los cien niños». En realidad sus efectivos iniciales serían de unos dos mil militantes, pero su influencia tanto política como sindical era bastante limitada. Por su parte los partidarios de la III Internacional en el seno del PSOE quedaron en una posición un tanto incómoda, pero ello no les hizo flaquear en su proyecto de arrastrar al conjunto de su partido. Con el argumento de que el retraso del proyectado congreso de la II Internacional había puesto en cuestión la validez de los acuerdos tomados en diciembre, lograron que la cuestión se debatiera de nuevo en un segundo congreso extraordinario del PSOE, que se celebró en junio de 1920.

En dicho congreso no se discutió si se debia ingresar en la III Internacional, sino tan sólo las condiciones en que debia efectuarse el ingreso, pero de nuevo se adoptó una fórmula bastante ambigua. Se acordó el ingreso inmediato, pero sujeto a tres condiciones contrarias al espíritu prevaleciente en Moscú: la autonomía del PSOE en lo referente a la táctica de lucha, su derecho a revisar en sus congresos los acuerdos de la Internacional y su propósito de perseverar en el intento de unificar todas las fuerzas socialistas. Por su parte la UGT, que celebró su propio congreso poco después, rechazó por abrumador margen su ingreso en la III Internacional. 


\section{PRIMEROS CONTACTOS CON LA REALIDAD SOVIÉTICA}

En el verano de 1920 la situación era pues que existía ya un pequeño Partido Comunista Español y que tanto la CNT como el PSOE habían acordado su ingreso en la III Internacional, aunque faltaba hacerlo efectivo. Para ello se desplazaron por entonces a Rusia Ángel Pestaña, en nombre de la CNT, y una delegación del PSOE, integrada por Fernando de los Ríos y Daniel Anguiano, además de Ramón Merino, que acudió como representante del PCE.

La misión de Merino no planteó problemas: su partido fue reconocido como sección española de la Internacional Comunista y él regresó encantado de cuanto había visto en el país de los soviets ${ }^{8}$. En cambio las otras dos misiones revelaron la profunda diferencia que existía entre las culturas políticas predominantes en la CNT y el PSOE y la de los bolcheviques rusos, lo que representó un augurio de las dificultades que tendría el movimiento comunista para arraigar en España.

Pestaña, que fue encarcelado a su regreso, tardó mucho en exponer públicamente sus impresiones de Rusia, pues sólo lo hizo en un libro publicado en 1925, cuando hacía tiempo que en la CNT se había cerrado el debate sobre el tema, pero en su libro reveló una profunda decepción ante la realidad soviética ${ }^{9}$. Durante su estancia en Rusia pudo comprobar que alli se estaba construyendo una nueva sociedad, pero concluyó que la supuesta dictadura del proletariado era en realidad la dictadura arbitraria de un partido. Comprendió además que la CNT nada tenía que hacer en una organización política como la III Internacional y aunque suscribió el manifiesto fundacional de la Internacional Sindical Roja, destinada a coordinar a las organizaciones sindicales afines al espíritu de la revolución rusa, lo hizo advirtiendo que las referencias que en dicho manifiesto se hacían a la conquista del poder político resultarían inaceptables para la CNT ${ }^{10}$.

Los delegados socialistas se enfrentaron por su parte a una misión imposible, pues las tres condiciones adoptadas por el congreso de su partido eran frontalmente opuestas a las 21 condiciones de ingreso que, poco antes de su llegada, había adoptado el II Congreso de la III Internacional, en las que se enfatizaba el sometimiento a la disciplina internacional y se exigía a los partidos que quisieran incorporarse la expulsión de su ala mo-

\footnotetext{
Véase su informe en El Comunista, 5/3/1921

A. PEstaña (1925?): Setenta días en Rusia: lo que yo vi, Barcelona, Tipografía Cosmos.

Véase Memoria que al Comité de la CNT presenta de su gestión en el II Congreso de la III Internacional su delegado Ángel Pestaña, Madrid, Bibiloteca Nueva Senda.
} 
derada. Asi es que la respuesta oficial de la Internacional Comunista a la petición de ingreso del PSOE consistió en un llamamiento a los trabajadores españoles para que abandonaran a sus líderes reformistas. Para efectuar el ingreso no quedaba otra opción que la adhesión incondicional y la escisión del PSOE, una perspectiva que no resultaba grata ni siquiera a Anguiano, que era el dirigente en quien inicialmente Ramírez había pensado como el más adecuado para encabezar el Partido Comunista Español.

Anguiano no quedó del todo convencido por cuanto vio en Moscú. Aprobaba la dictadura del proletariado, pero dudaba que debiera ejercerla un partido e incluso llegó a comentar que en Rusia se vivía como en un presidio (opinión que tenía más valor porque él mismo había estado en presidio por su participación en la huelga general de 1917). Por su parte Fernando de los Ríos, en cuya concepción del socialismo se combinaban la sociología marxista y la ética kantiana, mostró su radical desacuerdo con varios aspectos fundamenteles de la experiencia soviética, primero en su discurso ante el decisivo congreso en que el PSOE debatió por última vez la adhesión a la III Internacional y pocos meses después en un libro que tuvo una gran repercusión ". Ríos se identificaba con el espíritu general de la revolución rusa y en particular con la creación de los soviets, en los que veía un órgano democrático de los trabajadores, pero condenó la dictadura de un partido que había amordazado la conciencia de la sociedad mediante un régimen de terror, anulando la libertad de expresión y la de asociación y privando de funciones reales a los sindicatos. “¿Llegará Rusia a comprender que la igualdad sólo puede ser buscada por la vía de la libertad?", se preguntaba.

\section{LA ESCISIÓN DEL PSOE}

EI PSOE rechazó definitivamente su ingreso en la III Internacional en el congreso extraordinario que celebró en abril de 1921, aunque ello le costó una inmediata escisión. Para entonces el movimiento obrero español habían entrado en una fase de declive, aunque las organizaciones socialistas lo padecieron menos que la CNT, y el entusiasmo por la Rusia soviética ya no era el de los años 1918 y 1919. La dureza de las 21 condiciones chocó a muchos socialistas que hasta entonces habian sido entusiastas de la revolución bolchevique, pero que no estaban dispuestos a aceptar la com-

\footnotetext{
1 F. DE los Rios (1921): Mi viaje a la Rusia sovietista, Madrid, Caro Reggio. Anguiano publicó varios artículos sobre su viaje a Rusia en El Socialista, en enero y febrero de 1921.
} 
pleta pérdida de autonomía del socialismo español. Uno de ellos, Luis Araquistain, escribió que el centralismo absorbente de las 21 condiciones llevaría «a la dictadura del Comité ejecutivo del Partido Comunista de Rusia, no sólo sobre el pueblo ruso, sino sobre todos los pueblos adheridos a la III Internacional» 12.

A comienzos de 1921 la situación internacional era también menos favorable a Moscú. La derrota del Ejército Rojo por los polacos en el verano de 1920, cuando se hallaba a las puertas de Varsovia, privó a aquél de su aura de invencibilidad y su intervención contra el gobierno menchevique de Georgia, en febrero de 1921, suscitó alguna crítica por parte de los socialistas españoles. El fracaso de la insurrección comunista alemana de marzo de 1921 demostró que la posibilidad de una revolución en Europa central se alejaba y la insurrección de los marineros de Kronstadt, ese mismo mes, supuso la prueba más clara de que algunos de los sectores que habían protagonizado la revolución de octubre estaban ahora dispuestos a tomar las armas contra la dictadura comunista. Desde el punto de vista del PSOE fue también importante que en febrero de 1921 surgiera una nueva opción que permitia evitar el dilema entre la II y la III, al fundarse la llamada Internacional de Viena, cuyo propósito era reconstruir la unidad del socialismo internacional.

La unidad del socialismo fue también el gran argumento que un Pablo Iglesias ya muy enfermo esgrimió en contra de la III Internacional en vísperas del congreso de abril de 1921, al que no pudo asistir. Pero el PSOE no pudo evitar la suerte que en meses anteriores habían sufrido el Partido Socialdemócrata Independiente Alemán y los partidos socialistas de Francia e Italia, todos los cuales se habían escindido. Cuando los partidarios de la Internacional de Viena se impusieron a los de la III Internacional, por el estrecho margen de 8.808 votos contra 6.025 , estos últimos anunciaron su abandono del PSOE. Curiosarnente lo hicieron por boca de Oscar Pérez Solís, un reciente converso al comunismo que no mucho antes había sido uno de los más firmes defensores de la permanencia del PSOE en la II Internacional y que no muchos años después se incorporaría a las filas de la derecha ${ }^{13}$.

Tras abandonar el congreso los delegados favorables a la III Internacional fundaron el Partido Comunista Obrero, cuyo nacimiento no fue acogido con simpatía alguna por sus jóvenes rivales del Partido Comunista

12 L. ARAauistain, «Las condiciones de Moscú», El Socialista, 15 y 20/10/1920

13 Véase su interesante autobiografía: O. PÉREz SOLis (1931?): Memorias de mi amigo Óscar Perea, Madrid, Renacimiento. 
Español. La unificación de ambos partidos, que resultaba obligada porque la Internacional Comunista sólo reconocía una sección en cada país, iba a resultar conflictiva.

Tras la escisión el PSOE siguió defendiendo en abstracto la revolución rusa, pero adoptó una actitud muy crítica hacia la dictadura comunista, que mantuvo todo a lo largo de los años veinte, y manifestó su identificación con los principios de la democracia liberal. En particular Pablo Iglesias, que falleció en 1925, insistió durante sus últimos meses de vida en el carácter "eminentemente liberal» del socialismo. Su línea de argumentación era que el liberalismo, correctamente entendido, implicaba la libertad de pensamiento y acción para todos y que esa era la aspiración del socialismo, que proseguiría su lucha para alcanzar el mayor grado de libertad posible en la sociedad burguesa, aunque sólo tras la abolición del capitalismo sería posible la plena libertad ${ }^{14}$.

\section{EL DESENCANTO DE LA CNT}

La inicial adhesión de la CNT a la Internacional Comunista había sido el resultado del entusiasmo de sus militantes por una revolución cuyos perfiles reales conocían mal. Luego el debate sobre el tema se centró en la dictadura del proletariado, lo que suponía plantearse si era posible la destrucción de la sociedad burguesa sin recurrir a procedimientos autoritarios, que en principio eran opuestos al ideal anarquista. Algunos opinaban que había que dejarse de idealismos y, llegado el momento de la revolución, recurrir a los mismos medios coercitivos que los rusos habian empleado para despojar a la burguesía ${ }^{15}$. Otros en cambio opinaban que la dictadura del proletariado como tal era imposible y que la dictadura de un partido más o menos revolucionario no era deseable, sino que deberian ser los propios obreros organizados en sus sindicatos los únicos reguladores de la vida social ${ }^{16}$. Y no faltaba quien argumentara que un auténtico anarquista no podía escoger entre el mal mayor de que la autoridad la ejerciera la burguesía y el mal menor de que la ejerciera el proletariado ${ }^{17}$.

Este debate se producía en el marco de la fuerte represión que se abatió sobre la CNT, especialmente en su bastión barcelonés, desde finales de 1920. Con sus más conocidos líderes encarcelados, sus sindicatos ce-

\footnotetext{
P. IGLesias, El Socialista, 12/10/1925.

A. CaRdona, Solidaridad Obrera, Bilbao, 7/1/1921

TEOCRITO, Solidaridad Obrera, Bilbao, 17/9/1920.

F. JORDAN (1920): La dictadura del proletariado.
} 
rrados, su prensa suspendida y sus militantes sometidos a las agresiones de los pistoleros de los Sindicatos Libres y de la propia policía, que asesinó a algunos detenidos, la CNT se debilitó con gran rapidez, aunque ello no evitó que continuaran los atentados de los grupos de acción anarquistas. El descabezamiento de la CNT favoreció por otra parte el ascenso a su dirección de jóvenes militantes muy identificados con la revolución rusa, como Andreu Nin, que se convirtió en su secretario general, y Joaquín Maurín, que se incorporó al comité regional de Cataluña. Esta nueva dirección, o alguno de sus miembros, fue responsable del asesinato del jefe de gobierno Eduardo Dato, efectuado en marzo de 1921 como represalia por la represión violenta que estaba sufriendo la CNT ${ }^{18}$.

Nin y Maurín fueron dos de los delegados que un pleno del Comité Nacional de la CNT, reunido en abril 1921, envió al I Congreso de la Internacional Sindical Roja, que se celebró aquel verano en Moscú, conforme al llamamiento que un año antes había suscrito Pestaña. El mandato que llevaban era el de defender la autonomía sindical, aceptar como objetivo la dictadura del proletariado, siempre y cuando fuera ejercida por los sindicatos, y aceptar también que se estableciera una coordinación entre la ISR y la Internacional Comunista. Pero el segundo elemento del mandato era incompatible con las tesis comunistas, contrarias a la primacía revolucionaria de los sindicatos sobre los partidos, por lo que difícilmente habrian podido lograr que el Congreso de la ISR lo adoptara. Nin argüiría, frente a las criticas que esto suscitó en la CNT, que en la ISR habían confluido dos tendencias, la sindicalista revolucionaria y la comunista, por lo que no se podía pretender que en ella se impusiera plenamente la ideología de la primera ${ }^{19}$. De hecho la ISR aceptó el papel dirigente del partido comunista.

Por otra parte la celebración de aquel congreso coincidió con la huelga de hambre de varios anarquistas rusos encarcelados en Moscú, en favor de los cuales intervinieron ante las autoridades soviéticas varios delegados. Particular interés por el tema demostraron Hilario Arlandis, delegado también de la CNT, y Gastón Leval, un francés arraigado en Cataluña que se había sumado a la delegación de la CNT en representación de los grupos anarquistas de Barcelona.

Leval regresó a España con una visión muy crítica del régimen soviético, mientras que Maurín, sin ocultar las dificultades por las que atravesaba

18 Según el testimonio del propio J. Maurin en España Libre, Nueva York, 3/6 y 5/8/1960, citado por V. Alba (1975): El marxisme a Catalunya, IV: Joaquim Maurín, Barcelona, Pòrtic.

${ }_{19}$ A. NIN, Lucha Social, Lérida, 27/8/1921. El informe de la delegación de la CNT al Congreso de la ISR se publicó en este mismo periódico en junio y julio de aquel año. 
Rusia, ofreció una valoración positiva del mismo. Junto a su obvia admiración por el colectivismo, Maurín mostró también su apoyo a ciertos rasgos, que hoy llamaríamos modernizadores, típicos de la sociedad soviética de los años veinte, como la emancipacićn femenina y la libertad sexual 20. Por su parte Nin, permaneció finalmente en Rusia, como funcionario de la ISR, pues su regreso a España era imposible al haber sido implicado en el asesinato de Dato.

El debate final sobre su adscripción internacional lo llevó a cabo la CNT en una conferencia nacional que, en una situación ya menos represiva, pudo celebrar en Zaragoza en junio de 1922. En ella la tesis contraria a la integración en organizaciones de orientación comunista, defendida por Ángel Pestaña y Salvador Seguí, se impuso por amplia mayoría a la que pretendía mantener la afiliación a la ISR, que sostuvo Arlandis, el único presente entre los delegados que habian viajado a Moscú en 1921. La conferencia también aprobó una protesta por la represión que en Rusia sufrían elementos de izquierda.

La simpatía por el experimento soviético que inicialmente predominara entre los anarquistas españoles había desaparecido para siempre. Uno de ellos explicó que nunca había esperado que la revolución rusa pudiera conducir a corto plazo a la deseada sociedad anárquica, pero que lo decepcionante habia sido comprobar que el nuevo Estado proletario no toleraba ni el libre pensamiento, ni la crítica, ni la educación libre, ni ningún organismo independiente ${ }^{21}$. $Y$ en pleno régimen de Primo de Rivera una publicación ácrata comentó que en Italia había una dictadura burguesa, en España una dictadura militar y en Rusia una dictadura obrera, pero que en Italia y España se podian publicar periódicos anarquistas y en Rusia no; allí a los anarquistas se los difamaba, se los deportaba y se los fusilaba ${ }^{22}$.

Hubo sin embargo un sector de la CNT que derivó hacia posiciones comunistas: el sector sindicalista revolucionario que tenía como dirigente más conocido a Joaquín Maurín. Influido por la lectura de Georges Sorel, Maurin defendía la tesis de que la violencia había de ser la base de la moral proletaria y creía por tanto que la aceptación de la democracia y de los procedimientos pacíficos había apartado al socialismo de la senda revolucionaria

20 LEVAL aiudió extensamente a su viaje a Rusia en sus memorias inéditas, que se conservan en el International Institute of Social History de Amsterdam y de las que ha publicado un extracto J. Paniagua (1974): "La visió de Gaston Leval de la Rússia soviètica el 1921», en Recerques, n. 1 , 3. Los comentarios de Maurín se hallan en varios artículos de Lucha Social, publicados a fines de 1921 y comienzos de 1922.

21 Cultura y Acción, 3/3/1923.

22 La Revista Blanca, 1/8/1924. 
durante el periodo de la II Internacional ${ }^{23}$. Los sindicalistas afines a Maurín confluyeron con el PCE en los Comités Sindicalistas Revolucionarios, que en respuesta a un llamamiento de la ISR se fundaron en una asamblea celebrada en Bilbao en diciembre de 1922, con el objetivo de actuar en el seno de la CNT. Esta última se hallaba sin embargo en pleno declive y los CSR no tuvieron un eco significativo en el movimiento obrero español.

\section{LA DEBILIDAD DEL PARTIDO COMUNISTA DE ESPAÑA}

La unificación del PCE y el PCO en el seno del Partido Comunista de España se produjo en noviembre de 1921, gracias a la mediación de un delegado que la Internacional envió a Madrid, el italiano Antonio Graziadei. Pero el nuevo partido, que surgía en un momento de declive del movimiento revolucionario tanto en España como en el conjunto de Europa, logró un escaso eco tanto político como sindical y se caracterizó por fuertes enfrentamientos internos, que se encargó de arbitrar otro delegado de la Internacional, el suizo Jules Humbert-Droz.

De acuerdo con las instrucciones de la Internacional, y en contra de las tendencias antiparlamentarias predominantes en la extrema izquierda española, el PCE participó en las elecciones de abril de 1921, pero ni uno sólo de sus 25 candidatos se acercó siquiera al número de votos necesario para ser elegido, mientras que el PSOE obtuvo siete escaños. Pero más grave que este fracaso electoral fue para los comunistas su incapacidad para consolidar la influencia que tenían en la Unión General de Trabajadores algunos miembros del PCO. A ello contribuyó un dramático incidente que se produjo en el Congreso de la UGT de noviembre de 1922, en el que en un altercado un comunista al que nunca se llegó a identificar disparó contra un joven miembro del servicio de orden ugetista, que cayó muerto. Tras ello el Congreso votó una resolución de condena contra el Partido Comunista de España, al que responsabilizó de lo ocurrido, y los quince sindicatos que se negaron a aceptarla fueron expulsados de la UGT. La campaña socialista de denuncia por este asesinato contribuyó a crear una imagen muy desfavorable de los comunistas, que en adelante quedaron privados de toda capacidad de acción en el seno de UGT.

Así es que el panorama que Humbert-Droz se encontró cuando llegó a España para participar en el II Congreso del PCE, que se celebró en Madrid en julio de 1923, distaba mucho de ser halagüeño. Según el informe

23 J. Maurin, La Batalla, 23/i y 1/2/1923. 
que envió a la Internacional, la influencia del partido sobre la clase obrera española y sobre la política general del país había disminuido sensiblemente. En la UGT se atravesaba un periodo de exclusión de los comunistas y en los medios anarcosindicalistas se vivían "las consecuencias nefastas de la táctica terrorista de Barcelona". Además el periodo de atracción de la revolución rusa había terminado, con el agravante de que socialistas y sindicalistas realizaban su campaña contra Rusia y el comunismo a través de unos diarios a los cuales el PCE sólo podía replicar mediante semanarios de corta tirada y escasa difusión. El propio Partido Comunista de España había contribuido a su aislamiento e ineficacia por sus errores y carencias, como el empleo de medios terroristas -que se habian traducido en tres o cuatro asesinatos de socialistas-, la insuficiente acción política, la deficiente organización y la indisciplina interna. El resentimiento creado por las polémicas entre el PCE y el PCO no se había superado y a ello se añadía la incomprensión entre los militantes que procedían del Partido Socialista y los que procedian de medios anarcosindicalistas ${ }^{24}$.

En tales circunstancias la persecución desencadenada contra el PCE por el dictador Miguel Primo de Rivera, quien declaró que su objetivo era luchar contra el comunismo, apenas modificó nada, porque éste era ya una fuerza marginal en España bastante antes del golpe militar de septiembre de 1923.

24 Este informe se halla reproducido en J. Humbert-Droz (1971): De Lénine a Staline: dix ans au service de l'Internationale Communiste, 1921-1931, Neuchatel, La Baconniere. 